American Journal of Economics and Business Administration 2 (1): 56-63, 2010

ISSN 1945-5488

(C) 2010 Science Publications

\title{
The Impact of Organizational Justice on Employee's Job Satisfaction: The Malaysian Companies Perspectives
}

\author{
Choong Kwai Fatt, Edward Wong Sek Khin and Tioh Ngee Heng \\ Faculty of Business and Accountancy, University of Malaya, Kuala Lumpur, Malaysia
}

\begin{abstract}
Problem statement: This research study analyzed the impact of organizational justice as encompassed by two components, namely distributive justice and procedural justice on employee's job satisfaction, organizational commitment, and turnover intention. This study revealed a positive and significant relationship showing that the foundation of an employee's job satisfaction and organizational commitment is within the application of both distributive and procedural justice, and this supports a significant negative relationship to turnover intention. Approach: This study included the design and distribution of a self-administered questionnaire to 300 Malaysian employees working for small and middle size companies in the Malaysia, Klang Valley. The sample consisted of managerial and non-managerial employees who volunteered to participate in this study. The results supported the hypothesis that distributive and procedural justice has significant relationship with employee's job satisfaction, organizational commitment and turnover intention. Result: This finding implied that the higher the level of employee's perception towards fairness to the means used to determine outcomes (procedural justice) and fairness of the outcomes employees receive (distributive justice) tended to increase the level of employees' job satisfaction, organizational commitment while reduces turnover intention. Therefore, organizations that take a proactive approach to understand employee's perceptions of distributive and procedural justice, and provide appropriate working environment can potentially reap benefits including cost associated to employee retentions. Conclusion: The findings in this study would help managers and business organization in Malaysia to formulate strategies that involved work factors such as distributive and procedural justice to improve the management of human resource development. These strategies would help in influencing positive behaviors among employees, and hence achieve effectiveness and high productivity in the organization. Therefore, it was worth the effort for the organization to train and educate their managers on the impact of perceptions of organizational justice on the motivation and commitment of their employees.
\end{abstract}

Key words: Organizational justice, job satisfaction, distributive, procedural justice

\section{INTRODUCTION}

The globalization trend, technology development, new business practices and technology continuously influence organizations in Malaysia. Many companies were also facing intensive challenge of improving the employee's job satisfaction, organizational commitment to gain the competitive advantage and retention of key employees in the organization. Successful organizations realized that employee retention was important to sustaining their leadership and growth in the marketplace (Mello, 2006).

Employees were more satisfied when they felt they were rewarded fairly for the work they have done by making sure rewards were for genuine contributions to the organization and consistent with the reward policies. The reward included a variety of benefits and perquisites other than monetary gains. Employees with higher job satisfaction was important as they believed that the organization would be tremendous future in the long run and care about the quality of their work; hence they were more committed to the organization, have higher retention rates and tend to have higher productivity (Ishigaki, 2004).

Committed employees were more likely to perform beyond the call of duty to meet customers' needs and were highly motivated to work to the best of their ability. These traits were crucial for continued customer commitment and ongoing revenue and growth for an organization. Committed employees remained in the employment of the company longer, resisted competitive job offers, did not actively look for other 
employment and recommend the company to others as a good place to work. The longer the companies kept their employees; there would be no need for additional expenditure to train new employees. Recent studies have shown that managers were able to reduce unwarranted employee turnover because the most important factors driving employee satisfaction and commitment were largely within the direct purview and control of the manager. These included providing recognition, regular feedback and ensuring fair compensation reflecting an employee's contributions and value to the organization (Insightlink Communication, 2004).

Employees in an organization have always been a key asset, as their departures could have a significant effect on the implementation of the organization's business plans and may eventually cause a parallel decline in productivity. As such, employee retention was important to the long-term growth and success of the company. Retaining the best employees would ensure customer satisfaction and effective succession planning (Mello, 2006). It would also improve investor's confidence, as they were concerned with the organization's capacity to perform in such ways that would positively influence the value of their investment in the company. Hence, there was no question that uncontrolled employee turnover could damaged the stability of the company and consequently the national economy.

This study seeks to answer the following research questions:

- Does distributive and procedural justice and affects employee's job satisfaction, organizational commitment and turnover intention for Malaysian employees

- Do what degree of the impact of distributive and procedural justice on employee's job satisfaction, organizational commitment and turnover intention for Malaysian employees

Below, we reviewed the literature and developed related hypotheses for the variables of interest, followed by the description of the sampling design, selection of measurement scales and data analysis techniques. Afterwards is a presentation and discussion of results, limitations of study and implications for practitioners and future research.

\section{Literature review:}

Organizational justice: For the past three decades, HR managers and researchers have recognized the important relationship between organizational justice and organizational effectiveness. According to Tang et al. (1996), there was one factor related to the distributive justice to which the extend how fairly employees were rewarded while there were five identified factors (aspects) of procedural justice, namely fairness, twoway communication, trust in supervisor, clarity of expectations and understanding of the performance appraisal process. They found that distributive justice was significantly related to satisfaction with pay, promotion, the performance appraisal, and organizational commitment while procedural justice were related to satisfaction with supervision, self reported performance appraisal rating, performance appraisal, commitment, and job involvement.

Meyer and Smith (2000) considered the justice climate of the procedural, interpersonal and the informational, and suggested that the provision of training of managers to ensure that all of their employees perceived fair treatment. Facilitating meetings where subordinates were able to express their opinions, and that needed information was well communicated, that explanatory role-playing was performed, and that interpersonal sensitivity was observed when providing performance appraisal feedback to subordinates. As well as establishing policies, that increased the likelihood of procedural and informational justice and rule satisfaction.

In addition, employees in more flexible plans were found to have higher perceptions of procedural justice than those in more traditional benefit plans (Cole and Flint, 2004; 2005). Flexible plans were involved in allocating employer contribution amounts by choosing benefits and coverage levels, and therefore employees were able to have control over benefit outcomes such as life insurance, long-term disability, health insurance, dental insurance, and pensions. Employers were becoming facilitators rather than providers of benefits in the flexible benefit plans. Hence, it may provide a higher perceived value of benefits because employees become more aware of the value of their benefits in terms employer's cost and coverage levels. Besides that, consistent treatment meant that all employees had the opportunity to make benefit choices and supplied with accurate information to use in making their benefit decisions. It was suggested that organizations take a proactive approach to understand how the employees determine their perceptions of procedural and distributive justice, and design a benefit plan accordingly, and this could increased the employees' perceptions of justice and ultimately reap the associated benefits including improved employee retention, enhanced ability to hire and increased benefits satisfaction. 
All of the studies reviewed above demonstrated that distributive and procedural justices were important in predicting employees' subsequent personal satisfaction and commitment to the organization. According to Tang et al. (1996), it was also important for organizations to ensure that they communicated the relevant information to employees. The improvement in the perceptions of informational justice as well as procedural justice is through information communicated by higher levels of management and by organizational policies and practices. Another aspect was two-way communication to identify the needs, desires, and expectations of employees, that helped them to achieve their goals and objectives, to recognize their achievements and their accomplishments, provide feedback, and allows for an employee's input. As such, performance appraisal criteria and possible rewards should be expressed to their employees clearly to enhance their understanding of the process and improving their performance and trust in managers. They have also suggested that by applying rules fairly and consistently to all employees and reward them based on performance and merit without personal bias, would have a positive perception of procedural and distributive justice, which might lead to a higher satisfaction, commitment and involvement. As well as procedural and distributive justice, 'interpersonal sensitivity" and the supply of information to employees, and adding that there is a great need of a focus on the actual presentation of needed information. Therefore, managers needed to understand employee's intention, values, and attitudes, to communicate clearly, to respect their wishes and to project courtesy and friendliness.

Based on the above literature, this study seek to investigate how significance was the perceptions of organizational justice on employee's job satisfaction, organizational commitment and turnover intention in the context of Malaysian employees. The following hypotheses were developed:

\section{Hypothesis 1:}

$\mathrm{H}_{0}$ : The two independent variables (distributive justice and procedural justice) do significantly explain the variance in job satisfaction in Malaysia

$\mathrm{H}_{1}$ : The two independent variables (distributive justice and procedural justice) do not significantly explain the variance in job satisfaction in Malaysia

\section{Hypothesis 2:}

$\mathrm{H}_{0}$ : The two independent variables (distributive justice and procedural justice) do significantly explain the variance in organizational commitment in Malaysia
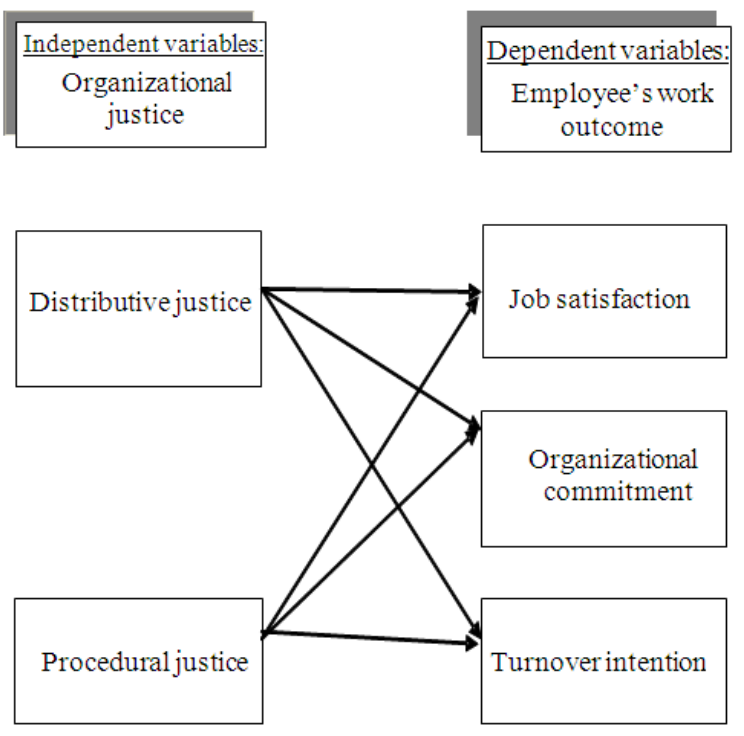

Fig. 1: Research model

$\mathrm{H}_{1}$ : The two independent variables (distributive justice and procedural justice) do not significantly explain the variance in organizational commitment in Malaysia

\section{Hypothesis 3:}

$\mathrm{H}_{0}$ : The two independent variables (distributive justice and procedural justice) do significantly explain the variance in turnover intention in Malaysia

$\mathrm{H}_{1}$ : The two independent variables (distributive justice and procedural justice) do not significantly explain the variance in turnover intention in Malaysia

The framework (Fig. 1) signified the research model for this research study. It was the outline for the research study that consisted of two major attributes, namely independent and dependent variables, which serves as guidelines for conducting the research study. The independent variables in this research study were components of organization justice, namely distributive justice and procedural justice, while dependent variable includes employee's work outcome, namely job satisfaction, organizational commitment and turnover intention.

\section{MATERIALS AND METHODS}

A distribution of three hundred self-administered questionnaires to the respondents who were working in the Klang Valley, Malaysia. The questionnaire was designed to test the three hypotheses was separated into 
two sections. The questionnaire consisted of 46 questions, whereby the first section obtained the demographic variables of the respondents such as gender, age, education level, current position and years of service with the organization, while the second section is to test the hypotheses.

In the second section, the questions consisted of five parts, namely job satisfaction, organization commitment, turnover intention, distributive justice and procedural justice. Respondents were required to rate their importance towards each factor based on Likert five-point scale ranging from "1-Strongly Disagree, 2Disagree, 3-Neutral, 4- Agree, 5-Strongly Agree”.

This self-administered questionnaire was to allow the researchers to collect relevant information to test the relationship between employee's perceptions of organizational justice and work outcomes. The measures of the dependent variables, namely job satisfaction, organizational commitment and turnover intention variables and independent variables, namely distributive and procedural justice in this research study have been modified from the scales adopted by Lee (2000) and was discussed as below:

- Job satisfaction was the mean of a 6-items scale that addressed the extent to which the respondent was satisfied with their overall job

- Measurement of organizational commitment was by a 6 -items scale that contained statements that described participants' commitment to the organization in which they work

- Measurement of turnover intention was by a 5items scale. Asking respondents to evaluate their likelihood of staying or leaving their work organization assessed loyalty

- Measurement of distributive justice was by using the mean of a 5-items scale whereby the items described the respondent's perceptions that distribution of pay and benefits is fair and equitable compared to similar jobs externally and reflect on their performance appraisal

- Measurement of procedural justice was by a 19item list based on literature related to procedural justice, namely fairness (4-items), communication and employee's participation (7-items), performance appraisal (5-items) and trust (3-items)

\section{RESULTS AND DISCUSSION}

Results consisted of three sections to test Hypothesis 1 to 3 as below:
Result of Hypothesis 1: Table 1 showed the Pearson Correlation between distributive justice, procedural justice and job satisfaction. The value of Pearson Correlation equaled 0.282, which indicated a weak correlation between distributive justice and job satisfaction (Saunders et al., 2006). Result also indicated a positive relationship between distributive justice and job satisfaction. Since the p-value was less than 0.05 , hence there was significant relationship between distributive justice and job satisfaction with 95\% confidence level.

The value of Pearson Correlation equal 0.458, which indicated a fair correlation between procedural justice and job satisfaction (Saunders et al., 2006). Result also indicated a positive relationship between procedural justice and job satisfaction. Since the pvalue is less than 0.05 , hence there was significant relationship between procedural justice and job satisfaction with $95 \%$ confidence level.

From the results obtained in regression analysis as shown in Table 2 , the value of $R$ was 0.461 , value of $R^{2}$ equals 0.21 , which mean $21 \%$ of variation in job satisfaction was due to variation in distributive justice and procedural justice. The p-value is very low (less than $5 \%$ significance level), therefore accepted null hypothesis $\mathrm{H}_{0}$, whereby the two independent variables (distributive justice and procedural justice) did significantly explained the variance in job satisfaction. Hence, the model adequately explained the relationship between the job satisfaction, distributive justice and procedural justice.

From the result output, the value of the t-test statistics for 'distributive justice' was 0.734 and p-value was 0.46 (more than 5\% significance level), hence 'distributive justice' did not contribute significantly to the model. However, the value of the t-test statistic for 'procedural justice' was 4.977 and p-value was very low (less than 5\% significance level), hence 'procedural justice' did contribute significantly to the model.

Table 1: Correlation result for Hypothesis 1

\begin{tabular}{llll}
\hline & $\begin{array}{l}\text { Job } \\
\text { satisfaction }\end{array}$ & $\begin{array}{l}\text { Distributive } \\
\text { justice }\end{array}$ & $\begin{array}{l}\text { Procedural } \\
\text { justice }\end{array}$ \\
\hline Job satisfaction & 1.000 & 0.282 & 0.458 \\
Distributive justice & 0.282 & 1.000 & 0.516 \\
Procedural justice & 0.458 & 0.516 & 1.000 \\
\hline Corredion
\end{tabular}

Correlation is significant at the 0.01 level (2-tailed)

\begin{tabular}{|c|c|c|c|c|c|}
\hline & Beta & $\mathrm{t}$ & $\operatorname{Sig}(\mathrm{p})$ & $\mathrm{R}$ & $\mathrm{R}^{2}$ \\
\hline $\begin{array}{l}\text { (Overall distribution } \\
\text { and procedural justice) }\end{array}$ & & & & $0.461(a)$ & 0.212 \\
\hline (Constant) & 1.646 & 6.396 & 0.000 & & \\
\hline Distributive justice & 0.049 & 0.734 & 0.464 & & \\
\hline Procedural justice & 0.451 & 4.977 & 0.000 & & \\
\hline
\end{tabular}


The explanation of the two independent variables is by using the multiple regression equation:

$$
y=a+\beta_{1} x_{1}+\beta_{2} x_{2}+\beta_{3} x_{3}+\beta_{4} x_{4}+\beta_{n} x_{n}
$$

Based on the beta coefficient from the Table 2, the regression weight for 'distributive justice' was 0.049 and 'procedural justice' was 0.451 . Hence, the multiple regression equation (fitted model) was as follows: $\begin{aligned} \text { Job Satisfaction }= & 1.646+0.049(\text { distributive justice })+0.451 \\ & (\text { procedural justice })\end{aligned}$

Based on the equation above, the relative predictive importance of the independent variables was established by comparing these beta weights, hence it could be concluded that among the two independent variables, procedural justice was more influential than distributive justice in predicting employee's job satisfaction. Note that distributive justice was not a significant predictor; therefore, there is partial supportive data for Hypothesis 1.

Result of Hypothesis 2: Table 3 showed the Pearson Correlation between distributive justice, procedural justice and organizational commitment.

The value of Pearson Correlation equal 0.456, which indicated a fair correlation between distributive justice and organizational commitment (Saunders et al., 2006). Result also indicated a positive relationship between distributive justice and organizational commitment. Since the p-value was less than 0.05 , hence there was significant relationship between distributive justice and organizational commitment with 95\% confidence level.

Table 3: Correlation result for Hypothesis 2

\begin{tabular}{llll}
\hline & $\begin{array}{l}\text { Organizational } \\
\text { commitment }\end{array}$ & $\begin{array}{l}\text { Distributive } \\
\text { justice }\end{array}$ & $\begin{array}{l}\text { Procedural } \\
\text { justice }\end{array}$ \\
\hline Organizational commitment & 1.000 & 0.456 & 0.475 \\
Distributive justice & 0.456 & 1.000 & 0.516 \\
Procedural justice & 0.475 & 0.516 & 1.000 \\
\hline Con
\end{tabular}

Correlation is significant at the 0.01 level (2-tailed)

Table 4: Multiple regression results for Hypothesis 2

\begin{tabular}{|c|c|c|c|c|c|}
\hline & Beta & $\mathrm{t}$ & $\operatorname{Sig}(\mathrm{p})$ & $\mathrm{R}$ & $\mathrm{R}^{2}$ \\
\hline $\begin{array}{l}\text { (Overall distribution } \\
\text { and procedural justice) }\end{array}$ & & & & $0.535(\mathrm{a})$ & 0.286 \\
\hline (Constant) & 1.020 & 3.589 & 0.000 & & \\
\hline Distributive justice & 0.261 & 3.544 & 0.001 & & \\
\hline Procedural justice & 0.401 & 4.007 & 0.000 & & \\
\hline
\end{tabular}

The value of Pearson Correlation equals 0.475, which indicates a fair correlation between procedural justice and organizational commitment (Saunders et al., 2006). Result also indicated a positive relationship between procedural justice and organizational commitment. Since the p-value is less than 0.05 , hence there was significant relationship between procedural justice and organizational commitment with $95 \%$ confidence level.

From the results obtained in regression analysis as shown in Table 4, the value of $\mathrm{R}$ was 0.535 , value of $\mathrm{R}^{2}$ equals 0.28 , which mean $28 \%$ of variation in organizational commitment was due to variation in distributive justice and procedural justice. The p-value was very low (less than 5\% significance level), therefore accepted null hypothesis $\mathrm{H}_{0}$, whereby the two independent variables (distributive justice and procedural justice) did significantly explain the variance in organizational commitment. Hence, the model adequately explained the relationship between the organizational commitment, distributive justice and procedural justice (there was a goodness of fit).

From the result output, the value of the t-test statistic for 'distributive justice' was 3.544 and p-value was very low (less than $5 \%$ significance level), hence 'distributive justice' did contribute significantly to the model. However, the value of the t-test statistic for 'procedural justice' was 4.00 and p-value was very low (less than 5\% significance level), hence 'procedural justice' did contribute significantly to the model.

The explanation of the two independent variables is by using the multiple regression equation:

$$
y=a+\beta_{1} x_{1}+\beta_{2} x_{2}+\beta_{3} x_{3}+\beta_{4} x_{4}+\beta_{n} x_{n}
$$

Based on the beta coefficient from the Table 4, the regression weight for 'distributive justice' is 0.261 and 'procedural justice' is 0.401 . Hence, the multiple regression equation (fitted model) was as follows:

$$
\begin{aligned}
\text { Organizational Commitment }= & 1.02+0.261(\text { distributive justice }) \\
& +0.401 \text { (procedural justice })
\end{aligned}
$$

Based on the equation above, the relative predictive importance of the independent variables was established by comparing these beta weights, hence it could be concluded that among the two independent variables, procedural justice was more influential than distributive justice in predicting employee's organizational commitment. The results show that the data supports Hypothesis 2. 
Result of Hypothesis 3: Table 5 shows the Pearson Correlation between distributive justice, procedural justice and turnover intention.

The value of Pearson Correlation equals -0.339, which indicates a fair correlation between distributive justice and turnover intention (Saunders et al., 2006). Result also indicates a negative relationship between distributive justice and turnover intention. When employee perception of distributive justice is high, their turnover intention will be low. Since the p-value is less than 0.05 , hence there is significant relationship between distributive justice and turnover intention with 95\% confidence level.

The value of Pearson Correlation equals -0.539 , which indicates a fair correlation between procedural justice and turnover intention (Saunders et al., 2006). Result also indicates a negative relationship between procedural justice and turnover intention. When employee perception of procedural justice is high, their turnover intention will be low. Since the p-value is less than 0.05 , hence there is significant relationship between procedural justice and turnover intention with 95\% confidence level.

From the results obtained in regression analysis as shown in Table 6, the value of $R$ is 0.544 , value of $R^{2}$ equals 0.29 , which means $29 \%$ of variation in employees' turnover intention is due to variation in distributive justice and procedural justice. The p-value is very low (less than 5\% significance level), therefore accept null hypothesis $\mathrm{H}_{0}$, whereby the two independent variables (distributive justice and procedural justice) do significantly explain the variance in turnover intention in Klang Valley. Hence, the model adequately explains the relationship between the turnover intention, distributive justice and procedural justice (there was a goodness of fit).

Table 5: Correlation result for Hypothesis 3

\begin{tabular}{llll}
\hline & $\begin{array}{l}\text { Turnover } \\
\text { intention }\end{array}$ & $\begin{array}{l}\text { Distributive } \\
\text { justice }\end{array}$ & $\begin{array}{l}\text { Procedural } \\
\text { justice }\end{array}$ \\
\hline Turnover intention & 1.000 & -0.339 & -0.539 \\
Distributive justice & -0.339 & 1.000 & 0.516 \\
Procedural justice & -0.539 & 0.516 & 1.000 \\
\hline
\end{tabular}

Correlation is significant at the 0.01 level (2-tailed)

Table 6: Multiple regression results for Hypothesis 2

\begin{tabular}{|c|c|c|c|c|c|}
\hline & Beta & $\mathrm{t}$ & Sig (p) & $\mathrm{R}$ & $\mathrm{R}^{2}$ \\
\hline $\begin{array}{l}\text { (Overall distribution } \\
\text { and procedural justice) }\end{array}$ & & & & $0.544(a)$ & 0.296 \\
\hline (Constant) & 5.355 & 16.433 & 0.000 & & \\
\hline Distributive justice & -0.087 & -1.027 & 0.306 & & \\
\hline Procedural justice & -0.706 & -6.149 & 0.000 & & \\
\hline
\end{tabular}

A dependent variable: Turnover intention
From the result output, the value of the t-test statistic for 'distributive justice' is -1.02 and p-value is 0.306 (more than 5\% significance level), hence 'distributive justice' does not contribute significantly to the model. However, the value of the t-test statistic for 'procedural justice' is -6.149 and p-value is very low (less than 5\% significance level), hence 'procedural justice' does contribute significantly to the model.

The explanation of the two independent variables is by using the multiple regression equation:

$$
y=a+\beta_{1} x_{1}+\beta_{2} x_{2}+\beta_{3} x_{3}+\beta_{4} x_{4}+\beta_{n} x_{n}
$$

Based on the beta coefficient from the Table 6, the regression weight for 'distributive justice' is -0.087 and 'procedural justice' is -0.706 . Hence, the multiple regression equation (fitted model) is as follows:

Turnover Intention $=5.355-0.087$ (distributive justice $)-$ 0.706 (procedural justice)

Based on the equation above, the relative predictive importance of the independent variables is established by comparing these beta weights, hence it can be concluded that among the two independent variables, procedural justice is more influential than distributive justice in predicting employee's turnover intention in Malaysia. Note that distributive justice is not a significant predictor; therefore, the data partially supported Hypothesis 3. Results presented the results of the statistical analyses of the hypotheses based on the data collected from the questionnaire. The relationship shown and discussed among the variables used the Pearson correlation analysis and multiple regressions. The analysis shows that the data partially supported Hypotheses 1 and 3 while the data supported Hypothesis 2.

\section{CONCLUSION}

Implications: This study provided some guidelines to assist managers to understand how to reduce employee turnover, increase job satisfaction and organizational commitments, by making better decisions about the outcomes and procedures for their employees. The research findings indicated the importance to include the management of both fair procedures and fair outcomes. These findings helped the managers to understand how fair judgments could contribute towards the effective management of workforce through implementation of organizational policies such as reward and performance evaluation policies. 
The results have several valuable practical implications for the managers. Managers need to apply rules fairly and consistently to all employees, and rewarding them based on performance and merit without personal bias in order to create a positive perception of distributive and procedural justice (Tang et al., 1996). The perceptions of unfairness can result in negative reactions to the organization, due to poor job satisfaction, commitment and turnover.

This research study also has several implications for managers concerned with the high economic costs of obtaining and retaining a committed workforce. The present findings suggest that procedural fairness has more effect on their job satisfaction, organizational commitment and turnover intention than distributive justice does. Hence, managers should be paying more attention to the means or the process of decision making for the distribution as it will leads to substantial pay-offs in individual job satisfaction, organizational commitment and turnover intention. Generally, the economic costs of acting in a procedurally fair manner such as treating individuals with respect and justification for actions are minimal when comparing to the cost of distributive fairness. Therefore, managers can influence important work attitudes through creation and maintenance of a procedurally fair climate.

As such, managers needed to nourish a procedurally fair climate environment in the organization by establishing two-way communication to allow their employees the opportunity to participate and voice their preferences and opinions during the decision making process (Wong and Teoh, 2009, Wong, 2006; 2007; Potter, 2006; Muhammad, 2004; Cole and Flint, 2005; Lemons and Jones, 2001). While management usually retained the prerogative to alter the policies and procedures, however, by informing the employees about possible changes and seeking their opinions of those changes might avoid deteriorating of their work attitudes. Therefore, the human resource played an important role in devising policies and procedures that are visible in demonstrating their commitment to open communication, empowerment and a just environment.

Limitations: This study has several limitations. First, the small sample size raises concern about sample bias. A number of factors may bias participants' responses. The present study has a number of methodological limitations that suggest areas for future research. There are several concerns when generalizing the findings from this study. First, the sample size was small and is limited to selected employees working in the Klang Valley, Malaysia due to time and cost constraints. In collecting the data, the researcher attempted to include a diverse range of organizations and employees in terms of demographic characteristics. This procedure has made the sample less concentrated on a specific factor and does not represent the random sampling procedure. Therefore, the interpretation of this sample is as a convenience sample. Although the sample of this study represents a wide range of industries, jobs, and ages of the working population, it is a self-selected sample. The results may not represent workers in areas in which widespread economic problems are prevalent in the Klang Valley.

Suggestions for future research: The present study also dealt with employees working for private companies, in which management practices are highly focused on visible performance of individual employees. However, government-related or other public organizations may view HR management systems differently from those in the private sector; hence, emphasis on individual performance may possess a lesser value. As such, further research is needed to examine the generalization of these findings to nonprofit and/or government organizations.

Therefore, a recommendation is that further research applies to other regions and environments:

- In other private sector organizations in other states in Malaysia, so that the findings can be generalized across the whole population of Malaysia

- In other nonprofit and government organizations in Malaysia

Future research should also attempt to achieve a larger random sample to determine whether general results apply to a larger population sample size.

Future researchers can improve the general application of the present study by replicating these results using other samples and other methods. Future research should also examine the effects of interpersonal and informational justice climates towards organizational outcomes such as job satisfaction, organizational commitment and turnover intention. Therefore, suggested suggestion is made that future research should consider experimental or longitudinal approach and other consideration in terms of subject and setting of the study to generalize the results that allow for reaching conclusions that are more concrete.

\section{REFERENCES}

Cole, N.D. and D.H. Flint, 2004. Perceptions of distributive and procedural justice in employee benefits: Flexible versus traditional benefit plans. J. Manage. Psychol., 19: 19-14. DOI: $10.1108 / 02683940410520646$ 
Cole, N.D. and D.H. Flint, 2005. Opportunity knocks: Perceptions of fairness in employee benefits. Compen. Benefits Rev., 37: 55-62.

Ishigaki, D., 2004. Effective management through measurement. http://www.ibm.com/developerworks/rational/libra ry/4786.html

Insightlink Communication, 2004. The state of employee satisfaction.

http://www.insightlink.com/employee_satisfaction. html

Lee, H., 2000. An empirical study of organizational justice as a mediator of the relationship among leader-member exchange and job satisfaction, organizational commitment and turnover intentions in the lodging industries. http://scholar.lib.vt.edu/theses/available/etd05012000-14210002/unrestricted/dissertation.pdf

Lemons, M.A. and C.A. Jones, 2001. Procedural justice in promotion decisions: Using perceptions of fairness to build employee commitment. J. Manage. Psychol., 16: 268-281.

Mello, J.A., 2006. Strategic Human Resource Management. 2nd Edn., Thomson, Mason, OH., pp: 213-320.

Meyer, J.P. and C.A. Smith, 2000. HRM practices and organizational commitment: Test of a mediation model. Can. J. Adm. Sci., 17: 319-331. DOI: 10.1111/j.1936-4490.2000.tb00231.x

Muhammad, A.H., 2004. Procedural Justice as mediator between participation in decision making and organizational citizenship behavior. Int. J. Commer. Manage., 14: 58-68.
Potter, P.W., 2006. Procedural justice and voice effects. J. Org. Cult. Commun. Conflict, 10: 33-61.

Saunders, M., P. Lewis and A. Thornhill, 2006. Research Methods for Business Students. 4th Edn., Prentice Hall, USA., pp: 514.

Tang, L.P., S. Baldwin and J. Linda, 1996. Distributive and procedural justice as related to satisfaction and commitment. Adv. Manage. J., 61: 25-31.

Wong, E.S., 2006. Action Research: A Post-Structural and Post-modern Dissertation. Centre of Reflective Practitioner Resources Publication, Perth, Australia, ISBN: 0-9775005-1-9, pp: 126-170.

Wong, E.S., 2007. Action Research in Social Science. Centre of Reflective Practitioner Resources Publication, Perth, Australia, ISBN: 978-09775005-2-9, pp: 113-120.

Wong, E.S.K. and N. H. Teoh, 2009. An in-depth study of assessing the factors affecting higher education in South-East Asia: A case study of two universities. South East Asian J. Manage., 3: 113-128. 